\title{
STUDIES WITH INTRA-ARTERIAL SUCCINYLCHOLINE AND ITS HYDROLYSIS PRODUCTS*
}

\author{
John C. Roberts, M.D., † AND David M. LittLe, JR., M.D.
}

IN THE COURSE of the past eight years, during which succinyl(di)choline has become established as a muscle relaxant drug of great utility in clinical anaesthetic practice, there have been numerous attempts to identify the causes of the occasional cases of prolonged relaxation resulting from its use. ${ }^{1-8} \mathrm{~A}$ number of clinical entities have been described which are at times associated with a dramatic prolongation of the muscle relaxant activity of succinyldicholine: these have inc'uded electrolyte derangements, acid-base imbalance, cachexia, impaired renal function, and abnormal cholinesterase activity. ${ }^{9}$ The present study is concerned not with these abnormalities, but with mechanisms by which succinyldicholine's action may be prolonged in the patient whose neuromuscular physiology is normal prior to the administration of this drug.

TThe cumulative effect of muscle relaxant drugs such as gallamine triethiodide and d-tubocurarine chloride is well recognized, and consequently the anaesthetist is on firm ground in his effort to limit total dosage of these drugs. In the use of succinyldicholine, however, cumulative effect was not widely recognized in the early years of its use; and at present the mechanisms by which its action persists longer than would have been expected, the fact that the nature of the block it produces changes with increasing dosage and duration of use, and the fact that the need for increasingly rapid administration reveals a type of tachyphylaxis ${ }^{10}$ are subjects for intense speculation and investigation.

The concept that the action of succinyldicholine upon neuromuscular transmission is as evanescent as the drug's hydrolysis is rapid, and that therefore no ceiling need be imposed upon clinical dosage, is no longer tenable. For, in fact, it has been demonstrated that the first-stage hydrolysis product of succinyldicholine, which is succinylmonocholine (Fig. 1), is itself a muscle relaxant drug of weaker but more prolonged action than its precursor. ${ }^{11}$ This information by itself would perhaps be sufficient reason for the limitation of total dosage of succinyldicholine, despite the fact that the monocholine ester is hydrolised in a reasonably short space of time. ${ }^{12,13}$ However, further reason for the limitation of total dosage is suggested by the discovery that choline, an hydrolysis product of both succinyldicholine and succinylmonocholine, also has significant actions upon neuromuscular transmission..$^{14-16}$

An extensive study of the effect of choline on neuromuscular transmission in the human has been carried out by Grob and his co-workers. ${ }^{14,16}$ Acetylcholine was

\footnotetext{
"Presented at the Second World Congress of Anaesthesiologists, Toronto, Canada, September $5-10,1960$.

†Present address: Addison Gilbert Hospital, Gloucester, Mass, U.S.A.

$\$$ From the Department of Anesthesiology, Hartford Hospital Hartford 15, Conn., U.S.A.
} 


\section{PATH OF SUCCINYLCHOLINE HYDROLYSIS}

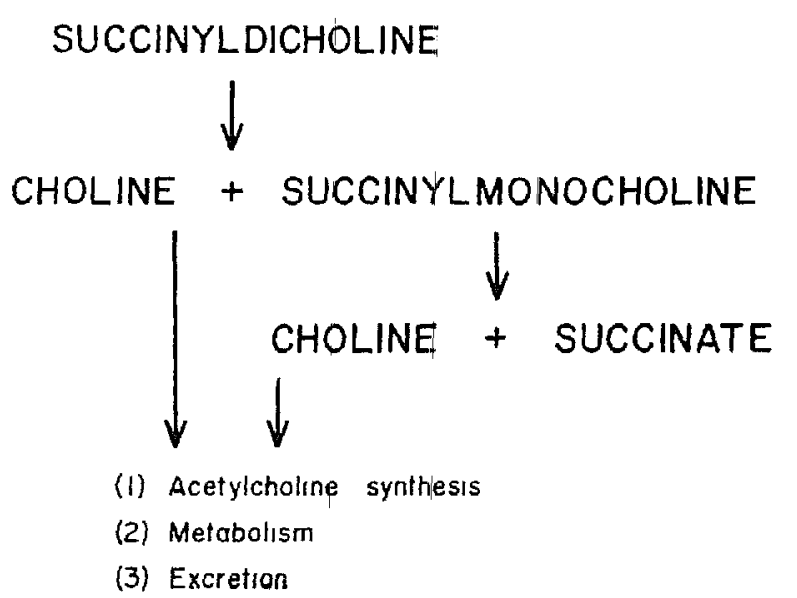

Figure 1. Hydrolysis of succinyldicholine to choline and succinylmonocholine, and the latter's further hydrolysis to choline and succinate.

administered intra-arterially and muscle action potentials were recorded after nerve stimulation: these experiments demonstrated that, following the administration of $1 \mathrm{mg}$. of acetylcholine and the immediate reaction to it, there existed a secondary depression of action potentials which lasted from 30 minutes to one hour, apparently due to the choline moiety released_in the course of the hydrolysis of acetylcholine: as the dosage of choline was increased, the characteristics of the neuromuscular block changed from those of a depolarizing type to those competitive block. It is worth noting that the amounts of choline released by the hydrolysis of acetylcholine in these experiments were very small in comparison to the amounts that would be released by the hydrolysis of a clinical dose of succinyldicholine, which is 80 per cent choline by weight.

Hutter $^{15}$ also has studied the effect of choline on neuromuscular transmission, and, using the anaesthetized cat as a subject, has demonstrated similar response to the administration of choline intra-arterially. He observed three different types of response to choline, depending upon the size of the dose: in low dosage, choline appeared to potentiate neuromuscular transmission, an effect ascribed to the repetitive response of individual fibers to a single nerve stimulus; with a larger dose, this potentiation was followed by depression of neuromuscular transmission; and with the largest doses, fasciculations occurred in the muscles supp'ied by the artery employed for the injection, and then depression ensued.

Studies on the fate of choline when administred orally and intravenously in $\operatorname{man}^{17,}{ }^{18}$ reveal that it is excreted unchanged in the urine in only small amounts, and that there is an absence of any symptoms referable to an effect on neuromuscular transmission when over $2 \mathrm{gm}$. of choline chloride are administered intravenously. In view of the effect produced by as little as $0.8 \mathrm{mg}$. of choline given intra-arterially in Grob's studies, ${ }^{16}$ it would appear that there is a mechanism for very rapid binding or clearing of excess choline in the circulatory tree. 
Normal choline plasma levels were found by Bligh to be 1.1 to $2.1 \mu \mathrm{g}$ per $\mathrm{ml}$., remaining very constant in the same individual over prolonged periods of time. ${ }^{19}$

The present study was undertaken to investigate further the effects of choline upon neuromuscular transmission, in an attempt to point to a correlation between prolongation of the action of succinyldicholine and the accumulation of its hydrolysis products, particularly choline.

\section{Methods and Material}

Cats were anaesthetized with intravenous pentobarbital, in a dosage of :20 $\mathrm{mg}$./kg., with small subsequent doses when needed, and the nerve supply to the anterior tibial group of muscles was exposed and stimulated electrically at varying rates, the individual stimuli being supramaximal. Muscle action potentials were recorded from electrodes on the tibialis anticus, being read visually from an oscilloscope screen which was calibrated frequently with stimuli of known strength; gross estimates of muscle activity were also made, the best, and surprisingly consistent, means of determination being the extent to which the movement of a twitch was transmitted to the fur of the paw, lower leg, and thigh. The femoral artery in the upper thigh was employed as the route for intraarterial injections of the salts of succinyldicholine and choline, and of the iodide salt of succinylcholine: chloride dosages mentioned refer to the amount of the salt.

\section{Intravenous and Intra-arterial Succinyldicholine}

Intermittent intravenous doses of succinyldicholine were administered in amounts of $.06 \mathrm{mg}$. $/ \mathrm{kg}$, and the doses. were spaced about 10 to 14 minutes apart (Fig. 2). The response to each injection was quite uniform, and within seven to ten minutes after each injection the muscle action potential returned to about 75 per cent of its control value and the strength of the muscle twitch in response to stimulation returned to an approximately normal value.

The response of the muscle to repeated intra-arterial administrations of succinyldicholine in a dosage of $0.05 \mathrm{mg}$. $/ \mathrm{kg}$., using a fresh animal, was strikingly different (Fig. 3). After the second injection of $0.12 \mathrm{mg}$., the gross estimate of muscle strength in response to stimulation climbed fairly rapidly toward normal; however, the length of time after the third injection until the first faint twitch increased from the previous five minutes to eight minutes, and the time taken for recovery to a normal response from this faint twitch increased from the previous three or four minutes to eleven minutes. Paralysis was complete after all these intra-arterial doses, whereas there was always a detectable twitch and accompanying muscle action potential after intravenous doses.

A large ( $1 \mathrm{mg}$.) dose in the same animal, given by the same intra-arterial route, produced severe weakness of the muscle for over one hour, and evidence of muscle fatigue at the end of this period of time.

\section{Intra-arterial Succinylmonocholine and Choline}

Succinylmonocholine produced two noticeable effects. First of all, when it was given in a dosage calculated to be such as would be released by hydrolysis 


\title{
MUSCLE ACTION POTENTIALS \\ AFTER INTRAVENOUS SUCCINYLCHOLINE
}

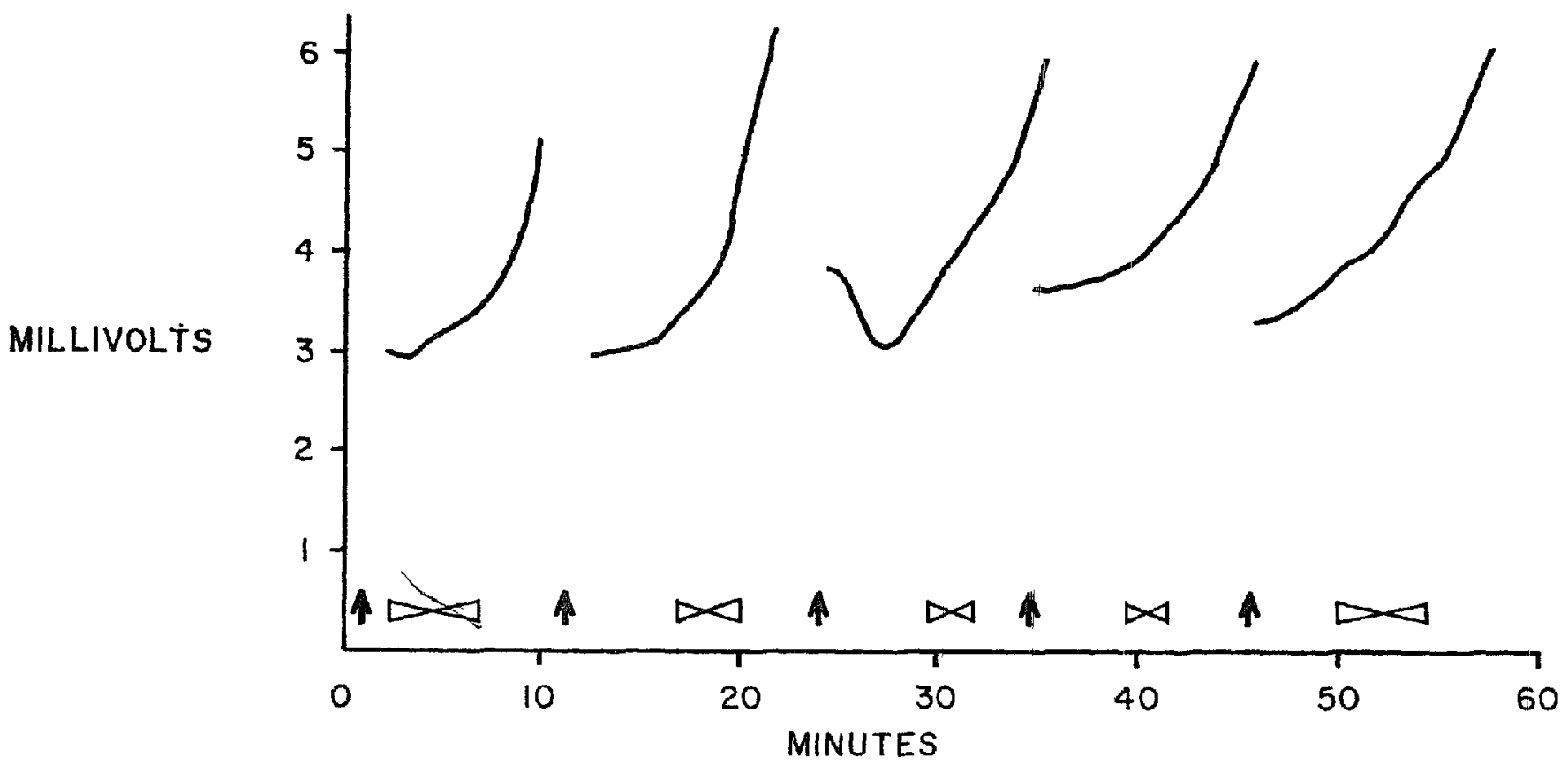

\author{
$=0.2 \mathrm{mgm}$. Succinyldicholine \\ $\bowtie=$ Interval between beginning of -recovery and gross estimate of \\ normal strength
}

Frgure 2. Effect of intermittent intravenous doses of succinyldicholine $(0.06 \mathrm{mg} . / \mathrm{kg} .)^{4}$ the muscle action potential of tibialis anticus of the cat. Note the comparative uniformity of response to each injection, with the return of the muscle action potential to about 75 per cent of its control value within seven to ten minutes after each injection.

of the amounts of succinyldicholine given intra-arterially as described above, the recovery of the muscle action potential following stimulation had reached about 50 per cent of its normal value at six minutes, at which time it was noted that different frequencies of stimulation produced responses of different magnitude: stimulation at 0.1 -sec. intervals gave a muscle action potential that was consistently higher than that given by stimulation at either $0.05-\mathrm{sec}$. or 0.25 -sec. intervals. Repeated stimulation then resulted in definite fatigue and recovery was not complete until 30 minutes after the succinylmonocholine injection. Secondly, after intra-arterial succinylmonocholine in the same dosage, an intravenous injection of succinyldicholine $(0.06 \mathrm{mg}$. $/ \mathrm{kg}$.) produced weakness for 20 minutes in contrast to the 11 minutes produced previously by this dose of succinyldicholine alone. When the intravenous succinyldicholine was given, fasciculations were noted only in the limb that had not been subjected to the previous intraarterial dose of succinylmonocholine.

The most evident effect of choline was recorded in an experiment in which a dose of succinyldicholine was administered intravenously $(.25 \mathrm{mg} . / \mathrm{kg}$. $)$, followed by choline administered intra-arterially $(1.25 \mathrm{mg} . / \mathrm{kg}$. $)$, and then, finally, the 
MUSCLE ACTION POTENTIALS

AFTER INTRA-ARTERIAL SUCCINYLCHOLINE

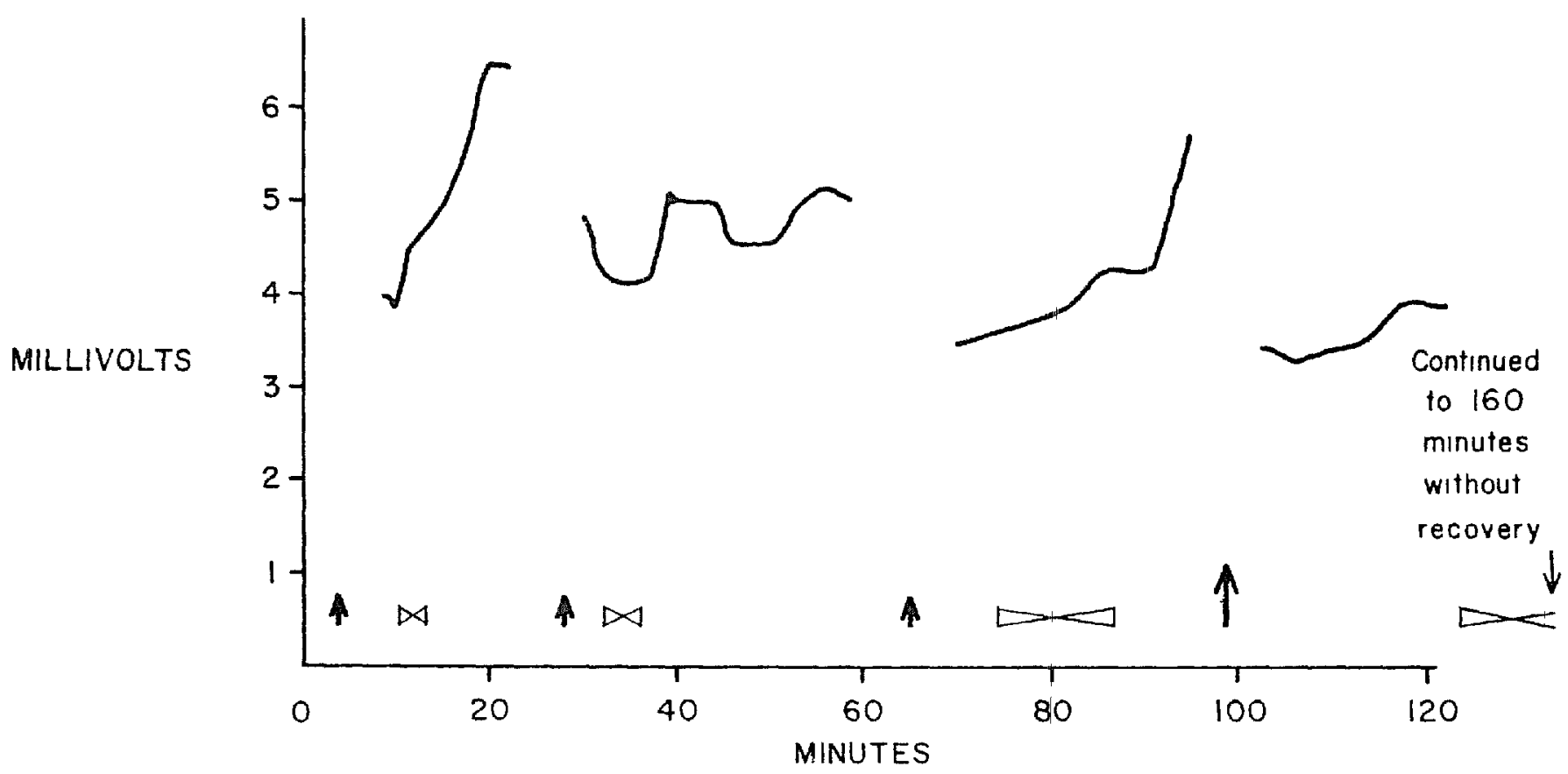

$$
\begin{aligned}
A & =0.12 \mathrm{mgm} . \text { Succinyldicholine } \quad \uparrow=1.0 \mathrm{mgm} \text { Succinyldicholine } \\
& =\begin{array}{c}
\text { Interval between beginning of recovery and gross estimate of } \\
\text { normal strength }
\end{array}
\end{aligned}
$$

FIGURE 3. Effect of intermittent intra-arterial doses of succinyldicholine $(0.05 \mathrm{mg} . / \mathrm{kg}$.$) on$ the muscle action potential of tibialis anticus of the cat. Note the increasing time interval between beginning of recovery and gross estimate of normal strength, and the very prolonged effect of a large (1 mg.) dose. See text.

first dose of succinyldicholine was repeated intravenously (Fig. 4). The choline produced a gradual, though not marked, decrease of the recorded muscle action potential; and at the same time a marked fatigue-ability was evidenced, such that stimulation had to be abandoned for approximately 10 minutes. The final dose of succinylcholine was associated with an exceedingly slow recovery: at the end of 32 minutes there was but the faintest of muscle twitches detectable in response to stimulation, and the muscle action potential was correspondingly small.

\section{Discussion}

Two features of the action of succinyldicholine and its hydrolysis products are suggested by these admittedly brief investigations.

First, these studies would be most compatible with the view that the intensity and duration of paralysis following succinyldicholine administration is more closely related to the maximum concentration to which the neuromuscular junction is exposed than to the over-all amount of relaxant administered. This would apply only when the total dose is low enough not to create a dual block, with all of the latter's uncertainties as to duration. The intensity and duration of 


\section{MUSCLE ACTION POTENTIALS \\ AFTER INTRAVENOUS SUCCINYLCHOLINE \\ AND INTRA-ARTERIAL CHOLINE}

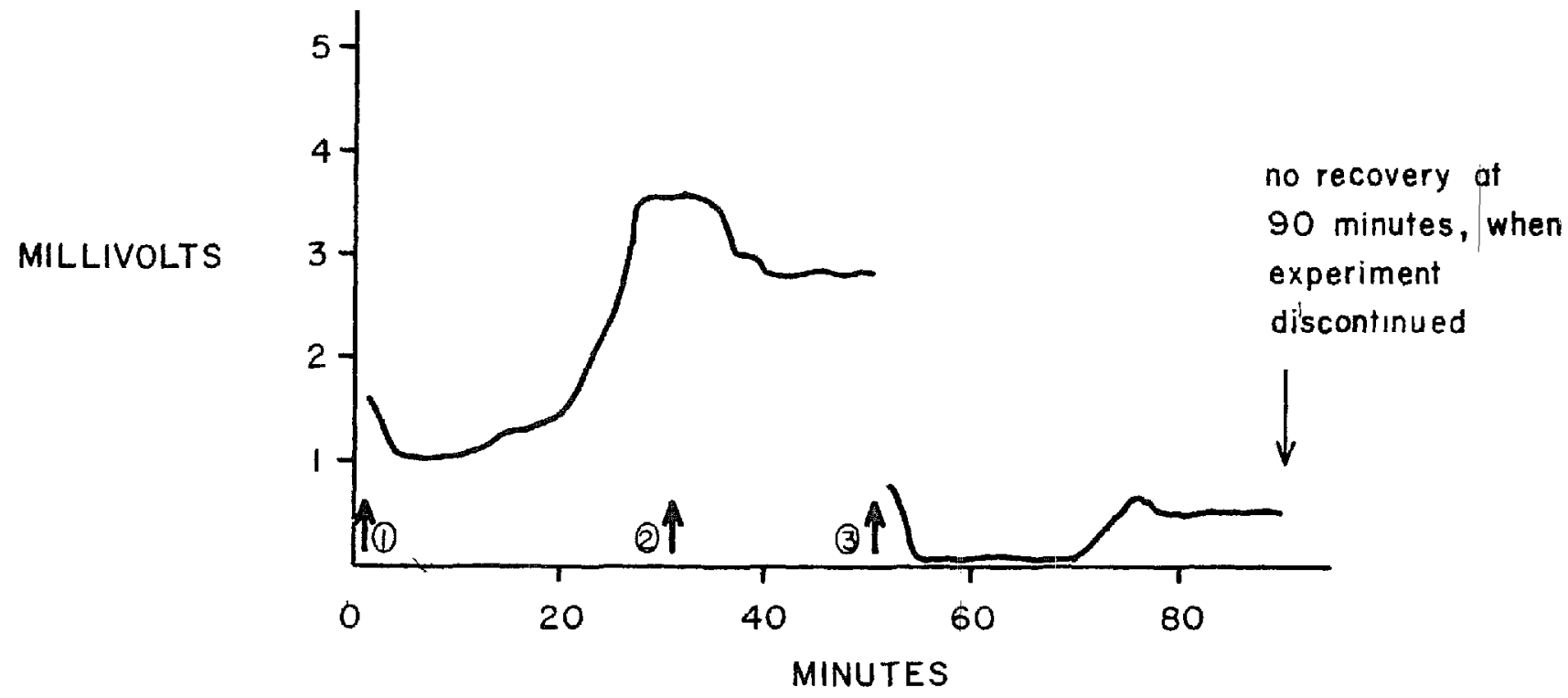

(1) $0.5 \mathrm{mgm}$. Succinyldicholine intravenously

(2) $2.5 \mathrm{mgm}$. Choline intra-arterially

(3) $0.5 \mathrm{mgm}$. Succinyldicholine intravenously

Figure 4. Effect of an intra-arterial dose of choline $(1.25 \mathrm{mg} . / \mathrm{kg}$.$) following an intraven$ dose of succinyldicholine $(0.25 \mathrm{mg} . / \mathrm{kg}$.), and its profound effect on a subsequent repetition or the intravenous dose of succinylcholine. See text.

muscle paralysis was markedly greater after intra-arterial injection than after the use of the same dose intravenously. It has been shown by the use of radioactive tracers, that iodocholinium, a muscle relaxant of the depolarizing type, is bound at or near the endplate. ${ }^{20}$ It is worth noting in this regard that it is the choline moiety of iodocholinium which is detected as "bound" to the endplate region, and perhaps even to the muscle fibre itself.

Second, although choline chloride, when given intra-arterially in these experiments, in a dose of $1.25 \mathrm{mg} . / \mathrm{kg}$. to a fresh animal, produced no effect dependable enough to warrant description, nevertheless, when either choline or succinylmonocholine was given intra-arterially and then succinyldicholine was given, there was a delayed recovery and evidence of fatigue on repeated stimulation.

This phenomenon may have its clinical counterpart in the patient who, after succinyldicholine administration, shows a strong cough at extubation and yet is unable to sustain adequate respirations in the face of even slight respiratory obstruction. The succinylmoncholine or choline would, in such an instance, be derived from hydrolysis of the succinyldicholine that had been administered. It also raises a question as to the validity of the estimation of muscle strength from the tidal volume of unobstructed respiration. It would seem that the most 
striking action of the intra-arterial administration of choline in these experiments is not one of direct paralysis, but rather lies in its effect upon the action of a subsequent dose of succinyldicholine. The mechanism by which choline produces these effects is not clear. Hutter's experiments ${ }^{15}$ suggest that the facilitation of neuromuscular transmission following the administration of small intra-arterial doses of choline in the cat is due to the ability of choline to cause an elevation of the resting endplate potential from the normal $-90 \mathrm{mv}$. to a figure closer to zero, and at the same time to lower the critical potential at which depolarization becomes self-sustaining to a value slightly nearer the resting potential. The net effect might be that less depolarization is necessary to produce a twitch in such a fibre.

One hypothesis to explain the mechanism of action of choline is that this substance is bound to the endplate region, where it has a weak nnitial depolarizing action and occupies the receptor areas upon which acetylcholine would normally act. This could result in the blockade of neuromuscular transmission, and is what appears to occur when the endplate is exposed to large amounts of choline. When the endplate is exposed to lower concentrations of choline (perhaps those concentrations normally produced in the hydrolysis of acetylcholine) an effect on the muscle membrane may be produced, as described by Hutter, in which a lesser degree of additional deplorization is required to produce a muscle contraction, and hence either exactly balances out the blocking effect, producing no normally detectable change in transmission from nerve to muscle, or produces an actual facilitation. The fact that choline possesses the property of curare reversal, ${ }^{15}$ in the cat at least, would appear to support this hypothesis, for the curare molecules may prevent choline from exerting its blocking effect and its facilitating effect is then predominant.

\section{SUMMARY}

In view of experimental work that has pointed to an effect of choline at the neuromuscular junction, and in view of the release of this chemical in the circu'atory bed and tissue spaces upon hydrolysis of succinyldicholine, experiments have been conducted to investigate the possible interaction of choline with succinyldicholine.

The experimental conditions obtained were not sufficiently accurate to warrant conclusions as regards the action of choline directly, and the reader is referred to the detailed and careful studies carried out by Hutter ${ }^{15}$ in England and Grob, Johns, and Harvey in Baltimore ${ }^{14,16}$ on the action of choline. A marked interaction between choline and subsequently administered succinyldicholine was noted, however, and a hypothesis for the mechanism of action of choline under such circumstances has been presented.

The release of choline by hydrolysis of succinyldicholine and succinylmonocholine is suggested as one cause for prolongation of neuromuscular block during clinical anaesthetic administration of succinylcholine.

\section{Resume}

A la suite de l'administration de doses cliniques de succinylcholine, on a observé un certain nombre de cas de paralysie musculaire prolongée dont les 
uns ont été mis sur le compte d'un deséquilibre electrolytique, les autres, d'un déséquilibre acide-base, d'une cachexie, d'une fonction renale perturbée,ou encore d'une activité anormale de la cholinestérase. Nous savons maintenant que la succinylmonocholine, un des produits d'hydrolyse de la succinylcholine est ellemême un myorésolutif dont l'action est plus faible mais plus prolongée que son précurseur. Nous savons aussi que la choline, un autre produit de l'hydrolyse de la succinylcholine (aussi bien que la succinylmonocholine) peut produire un effet à la jonction myoneurale, et c'est pour etudier l'interaction de la choline et de la succinylcholine que nous avons entrepris cette elude.

A la suite d'injections intra-veineuses et intra-arterielles de succinylcholine et d'injections intra-arterielles de chlorure de choline, nous avons enregistre les potentiels d'action musculaire par des électrodes sur le tibialis anticus du chat. Nous avons démontre que l'effet myoresolutif de la succinylcholine était plus prononcé lorsque la choline est presente à la jonction myoneurale (à la suite d'injection intra-artérielle de choline).

La libération de choline par l'hydrolyse de la succinylcholine et la succinylmonocholine sont, nous en avons l'impression, une cause de la prolongation du blocage neuromusculaire, lorsque l'on se sert de la succinylcholine au cours de l'anesthésie.

\section{REFERENCES}

1. Evans, F. T.; Gray, P. W. S., Lehmann, H.; \& Silk, E. Sensitivity to Succinylcholine in Relation to Serum-cholinesterase. Lancet $i$ : 1229 (1952).

2. Sairth, D. L., \& Virtue, R. W. Succinylcholine: Case Report and Experimental Study. Anesthesiology 15: 42 (1954).

3. Inwin, R. L., Wells, J. B., \& Whitehead, R. W. Effect of Calcium on Duration Apnea Induced by Succinylcholine. Anesthesiology 17: 759 (1956).

4. Hodges, R. J. H., \& Foldes, F. F. Interaction of Depolarizing and Non-depolarizing Relaxants. Lancet $i$ : 788 (1956).

5. ViRtue, R. W. Hazards and Safeguards In the Use of Chlorpromazine and Other Relaxing Agents In Anesthesia. Surg. Clin. N. A. 37: 1439 (1957).

6. Jowell, D. B., \& Woon-Smith, F. G. Prolonged Respiratory Depression Following Suxamethonium Chlorıde Due to Dual Block. Brit. J. Anaesth. 29: 13.3 (1957).

7. Foldes, F. F., Rendell-Baker, L. \& Birch, J. H. Causes and Prevention of Prolonged Apnea with Succinylcholine. Anesth. \& Analg. 35: 609 (1956).

8. Foldes, F. F. Muscle Relaxants In Anesthesiology. Ist ed Springfield, Ill.: Charles C. Thomas (1957).

9. Kalow, W., \& Staron, N. On Distribution and Inheritance of Atypical Forms of Human Serum Cholinesterase, As Indicated by Dibucaine Numbers. Canad. J. Biochem. Physiol. 35: 1305 ( 1957).

10. Foldes, F. F. Factors Which Alter the Eftects of Muscle Relaxants. Anesthesiology 20: 464 (1959).

11. Elirs, C. H.; Wnuck, A. L; Fanelli, R. V.; \& de Beer, E. J. Comparative Pharmacological Study of Mono and Dicholine Esters of Succinic Acid. J. Pharmacol. \& Exper. Therap. 109: 83 (1953).

12. Whittaker, V. P., \& WiJesundera, S. Hydrolysis of Succinylcholine by Cholinesterase. Biochem. J. 52: 475 ( 1952 ).

13. Tsuji, F. I.; Foldes, F. F.; Van Hees, G. R.; \& Shanor, S. P. Further Studies on Hydrolysis of Succinylmonocholine in Human Plasma. J. Pharmacol. \& Exper. Therap. 113: 51 (1955).

14. Grob, D., Johns, R. J., \& Harvex, A. M. Studies in Neuromuscular Function. IV. Stimulating and Depressant Effects of Acetylcholine and Choline in Patients with Myasthenia Gravis and Their Relationship to the Defect in Neuromuscular Transmission. Bull. Johns Hopkins Hosp. 99: 153 (1956). 
15. Hutrer, O. F. Effect of Choline on Neuromuscular Transmission in Cat. J. Physiol. 117: 241 (1952).

16. Grob, D., Johns, R. J., \& Harvey, A. M. Studies in Neuromuscular Function. III. Stimulating and Depressant Effects of Acetylcholine and Choline in Normal Subjects. Bull. Johns Hopkins Hosp. 99: 136 (1956).

17. DE LA Huenga, J., \& Poppen, H. Urinary Excretien of Choline Metabolites Following Choline Administration in Normals and Patients with Hepatobiliary Disease. J. Clin. Investigation 30: 463 (1951).

18. de la Huerga, J., Poppen, H., \& Steigmann, F. Utinary Excretion of Choline and Trimethylamines after Intravenous Administration of Choline in Liver Diseases. J. Lab. \& Clin. Med. 38: 904 (1951).

19. Bligh, J. The Level of Free Choline in Plasma. J. Physiol. $117: 234$ (1952).

20. Taylor, D. B. The Mechanism of Action of Muscle Relaxants and Their Antagonists. Anesthesiology 20: 439 (1959). 